\title{
Severe brain injury after cardiac surgery in children: consequences for the family and the need for assistance
}

\author{
A M Menezes, E A Shinebourne
}

\begin{abstract}
Objective-To identify the short and longer term needs of parents whose children sustain severe brain injury after cardiac surgery and to determine what further measures could be of use to the family after such a catastrophe.

Design-Qualitative analysis of data generated by semistructured interviews and a series of self report questionnaires.

Setting-Tertiary cardiothoracic referral centre.

Subjects-Group 1: four sets of parents (eight individuals) whose children had suffered severe brain injury after heart surgery; group 2: four sets of parents (seven individuals) caring for children with acute brain injury from other causes. Results-The data provide evidence of social, emotional, physical, practical, and financial difficulties. After the children suffered brain injury following cardiac surgery their parents did not receive information, support, and practical assistance as early as they needed it.

Conclusions-Although a small population was studied, it would seem that a structured, planned health care service response to this devastating event is not established; therefore, the needs of these parents are not well met. The parents and our inquiries suggest that a coordinator who is not attached to the hospital where brain injury occurred might optimally fulfil this role.

(Heart 1998;80:286-291)
\end{abstract}

Keywords: brain damage; cardiac surgery; parental support

This report is about parents whose children suffered neurological damage after cardiac surgery, because their particular needs have not been widely investigated. In the study we aimed to examine the consequences of such events and to discover how families might best be supported, immediately and in the longer term. Although parents of children with noniatrogenic brain damage were included for comparison, their situations are not reported here.

Most children who undergo heart surgery do well, but severe neurological damage is still a possible complication and there have been various investigations of its causes ${ }^{1-3}$ and prevalence. $^{45}$ This information, though vital, does not touch on the meaning of neurological complications for affected children and their families. Parents could therefore be an important, and complementary, source of information. With such information, professional carers might understand more about the impact of iatrogenic complications.

Families whose children are disabled or who live short lives because of brain damage, whatever the cause, frequently invest immeasurable effort to sustain their children. Many require more help. It is important that research continues to contribute to our understanding of the health related needs of such families, and examines critically the support that is currently received.

\section{Methods}

ETHICAL ISSUES

The research ethics committee of the hospital involved approved the study. It was recognised that potential subjects could be facing many emotional and social pressures. Therefore before participating, families were advised that this study would not have any impact on their own situations.

Several families that were identified as suitable candidates for this project were found to be involved in legal action. Hospital solicitors advised that where litigation was in progress no contact should be made. The concern was that the kind of communication proposed could be construed as interference with witnesses, so their advice was accepted.

\section{SUBJECTS}

Group 1-Parents with children brain damaged after heart surgery

The incidence of neurological complications following congenital heart surgery in children is unknown, ${ }^{5}$ although estimates have been made. ${ }^{4}$ To determine the population of such families at the source hospital, information was drawn from medical/nursing staff and computer databases, and cross checked with case notes. Thirteen families were found to match our criteria.

For legal reasons, only eight of the 13 potential subject families could be sent initial contact letters and five replied. One father returned his questionnaires with other written reports. $\mathrm{He}$ decided not to participate and refused consent for this information to be used, stating that the questionnaires were inadequate. Another family did not reply to any further correspondence. The wishes of these two families were respected. One mother from the source hospital suggested an extra contact. The child in this
Accepted for publication 30 March 1998 
Table 1 Group 1 parents

\begin{tabular}{llll}
\hline $\begin{array}{l}\text { Individual } \\
\text { codes }\end{array}$ & Sex & Interviewed & Questionnaires \\
\hline $1: 1$ & M & Yes & Yes \\
$1: 2$ & F & Yes & Yes \\
$1: 3$ & F & Yes & Yes \\
$1: 4$ & M & No & Yes \\
$1: 10$ & F & No & Yes \\
$1: 11$ & M & No & Yes \\
$1: 12$ & F & Yes & No \\
$1: 13$ & M & Yes & No \\
\hline
\end{tabular}

Table 2 Group 2 parents

\begin{tabular}{llll}
\hline $\begin{array}{l}\text { Individual } \\
\text { codes }\end{array}$ & Sex & Interviewed & Questionnaires \\
\hline $2: 5$ & F & Yes & Yes \\
$2: 6$ & F & Yes & Yes \\
$2: 7$ & M & No & Yes \\
$2: 8$ & F & Yes & Yes \\
$2: 9$ & M & Yes & Yes \\
$2: 14$ & F & Yes & Yes \\
$2: 15$ & M & No & Yes \\
\hline
\end{tabular}

family had brain injury after heart surgery at another centre. The parents agreed to participate. Therefore the final sample consisted of four sets of parents (eight individuals).

All of the subjects had children who were left with severe residual mental and physical disabilities after heart surgery. Table 1 is a summary of group 1 parents by their individual codes, sex, and the methods by which each contributed to this study.

Group 2-Parents with children brain damaged after "other" events

For comparison with the index families, we sought a second group of families whose children had suffered brain injury through various other causes. The Children's Head Injury Trust (CHIT) circulated a request for voluntary participation with their May 1996 newsletter. Five families responded. Of these five, one family did not respond to any further correspondence. The remaining four sets of parents (seven individuals) participated in the study. Three of the parents in group 2 were caring for children who were brain damaged by road traffic accidents, and one was damaged by a brain tumour and meningitis. The children had a range of mental and physical disabilities but were not as profoundly handicapped as the children in group 1 . Table 2 summarises group 2 parents by their individual codes, sex, and the methods by which each contributed to the study.

\section{PROCEDURES}

Subjects were offered the opportunity to contribute to the study by taking part in semistructured interviews or completing a series of self report questionnaires, or both. The questionnaires were: the psychosocial adjustment to illness: self report analogue scale (PAIS), ${ }^{6}$ the short form social support questionnaire (SF-SSQ), ${ }^{7}$ and a short series of questions designed by the investigators. Although data from the questionnaires have been analysed quantitatively, this paper reports only the find- ings generated by qualitative analysis. All data gathered from the subjects were analysed using techniques described by Coffey and Atkinson ${ }^{8}$ who stated,

'We do not simply 'collect' data; we fashion them out of our transcriptions with other men and women. Likewise, we do not merely report what we find; we create accounts of social life, and in doing so we construct versions of the social worlds and the social actors that we observe."

Semistructured interviews were used to facilitate detailed pictures of the subjects' experiences and to encourage each participant to take their own path within only limited guidelines. Because some parents were reluctant to take part in taped interviews, field notes were used to record discussions and other observations about each meeting.

These data were separated into the following categories: "emotional," "social," "physical," and "professionals." These initial groups were kept broad and simple to avoid judgment and to facilitate regrouping the data. Several subcategories emerged from these groups and these will be used to develop one description of the collective experiences of parents with brain injured children. Category headings were developed from the parents' own words as far as possible. Verbatim examples will be used so that the reader might hear them as the investigator did and thus develop a vivid understanding of the experiences and feelings shared. Examples are drawn from group 1 parents only.

\section{Results}

EMOTIONAL

Loss

Shock, loss, and grief were most commonly expressed by parents in group 1. They described deep sensations of loss at hearing that their child was brain damaged after cardiac surgery, an operation which they hoped would effect a "cure" and allow their child to lead a "normal" life. Some subjects combined these emotions with profound feelings of "aloneness." These issues were best summarised by a mother from group 1:

"The pain and loss we experienced after bringing our daughter home - even before that on the ward, when brain damage was clear-was made so much worse by having no one to talk to who we felt understood from their own experience." (Subject $1: 1)$

\section{Blame}

Guilt, blame, and anger were expressed by parents from both samples. Almost all subjects identified a specific focus of blame for their child's brain damage. These included "medicine," "the driver," "the child," and "themselves." However, parents in group 1 did not always express their feelings in direct ways. This was perhaps influenced by the researcher who represented the hospital responsible for their child's heart surgery and subsequent brain damage. One father began to raise this subject indirectly when he said:

"But sometimes I felt in a position of inferiority and obligation to medical staff. This made some questions hard to ask. Moreover you don't always know what to ask. For example, I won't ask 'is 
brain damage likely?' unless I have been told brain damage is possible." (Subject 1:1)

Another father from group 1 used the questionnaires to express his feelings like this:

"I don't have much faith in medical care and doctors. I was very unhappy with the treatment that my child received at the hospital who eventually referred her for surgery, they didn't do all they could have for us." (Subject 1:11)

Fear for one's sanity

This particular issue was only raised by subjects in group 1. They described emotional and physical exhaustion from the shock of hearing the diagnosis and from caring for their children alone at home. An example is provided:

".... Well it's like that, your feelings change all the time, from day to day, even from minute to minute at the beginning. It would have helped to know that what we felt was 'normal' not 'madness'." (Subject 1:3)

Fear of injuring the child

These issues, fear of injuring the disabled child and thoughts of euthanasia, were only raised by parents in group 1 . Subjects in group 1 seemed to accept the eventual death of their disabled children as an event that would bring true relief. They expressed pain and inner turmoil at these emotions but they shared them openly as these example demonstrate:

"The exhaustion is indescribable, endless sleepless nights. Some times you reach the point where you can do nothing but put your child down and escape for fear of doing something terrible." (Subject 1:1)

"It was her distress and obvious isolation in her body that made me consider trying to end her life. I think the things that stopped me were: fear of getting it wrong and causing her more pain, fear of moving on ahead of my husband, and fear of being judged unsuitable as a parent ... They weren't very high principles or moral reasons for not acting." (Subject 1:2)

Love

All the parents demonstrated love of their children. Those in group 1 went to great lengths to make their children as comfortable as they could. Those in group 2 spoke with pride about their children's achievements and with pain and love about the problems of letting disabled teenagers gain independence.

A mother from group 1 explained how one event had led her to develop her own level of acceptance and understanding:

"Sometimes it's the most ordinary things that make you stop and think, almost as if explaining it to someone else makes you see through it all. I remember once at the beginning my husband looked at our newly decorated room and said 'what is all this for?' At times you do wonder, when you have a child like this. I remember saying, 'it's so we can have some sunshine in our lives, so we can care for her in a happy home'. That is the only thing that makes life easier, if she is happy." (Subject 1:12)

SOCIAL

Isolation

Expressions of social isolation did not seem to vary between the two groups. Both made frequent references to the poor understanding of "outsiders" and therefore many wanted con- tact with others in situations like their own. One father said the following about the lack of understanding from "others" at the time of his child's brain injury:

"With friends/family there was, in my case at least, the feeling that often they did not have the time, did not appreciate the full gravity of the situation or did not want to hear the dreadful state of things. People always asked, 'How's your wife, how's the baby?'-but they never asked how I was. Did they presume my work distracted me to the point where I was unaffected?" (Subject 1:1)

Many of the parents expressed intense feelings of personal and social isolation, stating that even "other" people who wanted to comprehend really could not. It seemed that ultimately each parent was alone in his or her experience. For most, the personal pains of having "perfect" children irretrievably altered by brain injury were only ever partially or temporarily relieved. Some felt that sympathy, offered in abundance at first, gradually faded, leaving them with fewer and fewer "willing listeners."

The general experience of isolation was best summarised by this mother:

"The awful isolation that grief and exhaustion engender and the fear for one's sanity. All of these were so real and could have been a little more bearable, less frightening for me, if I had been able to meet or talk with people who had suffered a similar shock, loss, grief. I feel this would have been especially helpful in those first few months after discharge, when we felt so isolated." (Subject 1:2).

\section{Someone to talk to}

Parents clearly needed to communicate on many levels with someone they could trust, both at the time of the injury and afterwards. Those in group 1 made many references to this issue. One couple found it difficult to talk to hospital staff at the time of their child's surgery and subsequent brain injury because of constant interruptions to do what they called "physical, technical, medical, treatment related things" for their child. They felt that some health care workers did not have the skills or detachment to discuss the tragedy openly and to listen to their doubts, anxieties, or anger as parents. Although they knew no one could " $f i x$ their child and make things right," they still needed someone to listen and acknowledge how "bad and painful" their situation was.

In general parents wanted to build a trusting one to one relationship and were critical of the expectation that they could communicate effectively with a constantly changing string of people. It was frequently suggested that this person should be (1) detached from the child's care, (2) available on a regular basis, and (3) easy to reach as required. One mother explained simply, "we felt that we shouldn't keep making staff so sad."

The pain of retelling the story

Parents from both groups described the pain of retelling the story of their child's brain injury and disability to every new personal or professional contact. General emphasis on this theme did not seem to differ between the two groups. 
In general parents spoke of needing to "go into automatic pilot" or "tell it like a robot."

A father eloquently explained:

"You are on a journey with many stations, in order to explain your journey and where you are 'now' you miss out stations to make the story short, and to get the chance to say what your immediate need is ... but all of these stations feel vital to the whole journey, and to your child, so if you miss things out you feel like you are being unfair to your child. Then again, if you start at the beginning every time it becomes exhausting." (Subject 1:1)

The strange new person

Subjects from both groups referred to alterations in their children. Without direction most used photographs to illustrate these changes and to highlight the magnitude of their loss. Children from group 1 were babies at the time of surgery and their parents made simple descriptive references to the child they had known, as with this example:

"Yes, she has some characteristics which are the same as before. Little movements, the laughing, the energy. In many of those ways she is like my other children, and both of us. ..." (Subject 1:12)

Parents suffered anguish at not being able to comfort what one called "the strange, new, needy, demanding, little person," and frustration at the lack of support, which is demonstrated by the following example:

"But. . .when it's time to go home ... you are presented with this ...plank! (she then held her arms out in front of herself) and that's it! No practical advice, no information about where to get it-nothing!' (Subject 1:12)

Balancing the needs of various family members Mothers from both groups spoke about the difficulty of balancing the needs of other family members against the needs of their disabled children. They highlighted specific incidents when differences of opinion about their disabled child caused tension with partners. The following is an example:

"My husband and I felt different things at different times. He didn't agree that she should have died at the time of surgery. . . That's what I do feel now. Then another time we thought she might need a heart transplant and I agreed but he didn't. You just take it day by day really." (Subject 1:3)

All of the mothers made references to the problems of meeting the needs of their "other" children. All expressed notions that their other children did suffer in various ways. One mother explained simply:

"It helps to have two happy, healthy children and we do our best to make sure they don't miss out. They certainly do though, sometimes . . . You see, I don't have one special child, I have four special children." (Subject 1:12)

The child and the world

Parents in both groups commented on the societies within which their disabled children had to survive; however, the issues they raised differed considerably. Group 1 parents raised major questions about life, death, and the role of medicine, in contrast to those in group 2 who spoke about their child's future and explained their efforts to make society recognise and accept their children as valuable people.
The following example is representative of parents in group 1:

"In the end... you see, you are left alone to confront these questions of life and what quality of life, or death... Awful questions. We felt we faced them very much alone. I personally don't feel it's enough to pursue life at all costs, and yet I know that others feel differently. I think it is an important area of debate for us as a whole society, not just one to dump on doctors. Realistically though, doctors are in the front line. The conspiracy of silence that sometimes exists only contributes to the sense of isolation that people suffer." (Subject 1:2)

Money

Financial problems were mentioned by parents from both groups. Generally, they described their incomes as good or poor and combined this with examples of added costs, brought about by care of their disabled children. As with the following two examples, parents frequently found it difficult to discover what benefits they were entitled to:

"We get financial benefits now-but it is hard to find out what is available and how to apply for it. Everything costs. Some things we can't have because we work ... If we were unemployed we would get more. It would be nice if hospitals that perform surgery that goes wrong... like this, had a fund to help-you know just some help." (Subject $1: 3)$

"Financial pressure would be so easy to alleviate and yet it consumes so much time and energy when you are left to worry about it alone." (Subject 1:1)

PHYSICAL

Parents from both groups made little mention of their own physical needs, concentrating on those of their children although both are linked. When specifically asked about the impact of caring for disabled children on themselves, there were differences in the terms chosen by the two groups. Parents in group 2 used words like "tiring," a "drain," or a "strain." Those in group 1 tended to speak of "exhaustion," "wondering where the strength would come from to go on," and "living in shifts" around the needs of the disabled child. This may reflect the more severe disabilities of group 1 children and is illustrated by this mother's story:

"The other night I was so tired I barely had the energy to bathe her-but you have to. Her routines and her comfort are very important to her-in a way that's the only comfort we can give her. Without that she is restless and unhappy." (Subject $1: 12$ )

In most cases subjects felt that the demands of caring for a disabled child had some impact on interpersonal relationships. These effects were not always detrimental; in fact in some cases parents were brought closer together. However, it is important to note that parents used the questionnaires to express changes in sexual relationships and one mother reflected other stories when she wrote, "We have had little or no interest in sex since our child was born." (Subject 1:1)

PROFESSIONAL

The crisis period

All subjects described various contacts with "professionals." Group 2 parents tended to begin with the road traffic accident, the point of 
injury. However, group 1 parents began with their efforts to discover what was wrong with their child. The following is a typical example: "Well, at six weeks old she cried a lot and wasn't thriving. I felt sure something was wrong, I felt the doctors dismissed me as an older mum. You know. .. like 'older mums worry too much — try not to worry, nothing is wrong.' Finally she was referred to a specialist centre. They diagnosed an 'anomalous coronary artery'... Anyway, by then it was too late, she was too weak to take the surgery. I do feel that the time before the diagnosis was the worst of all ... like I was mad, why didn't they listen?" (Subject 1:3)

Parents in the same group also talked about the period immediately after surgery when brain injury was noticed. One father raised these questions:

"There was sometimes a tendency for health carers to focus on the 'treatment,' the cure of symptoms, but what about the child? What if we cure this infection? - So what, to what purpose! What quality of life is left? - That should be the question, not can we cure this infection but should we?" (Subject $1: 1$ )

The next example reveals that some parents received poor or inadequate professional support when the child returned home:

"Well actually you don't want other people to begin with, or you think you don't. When we got home the GP looked terrified at the heart surgery, let alone the brain damage. He asked what help we wanted! I wasn't sure what a physio, for example, might do for her. In the end we just said yes to everything; I figured we could discard what turned out to be useless." (Subject 1:12)

A picture of the roads ahead

In describing initial contact with professionals, parents in both groups wanted practical support, information, and honesty about the future. The two examples provided highlight these issues and reveal how important parents felt it was for this kind of support to begin as soon as possible:

"I wanted achievable goals. Something reachable. Otherwise I felt like I was hanging off a cliff (raised his arms upwards to demonstrate). I would rather someone said, look if she gets this far that's a good sign. Not goals so high she would never reach them . . . that would be too frustrating. Was too frustrating." (Subject 1:13)

"I recently met a mum and I told her everything I have found out along the way, over the years. If only someone at the original hospital could do that. That would be a really useful job for someone." (Subject 1:12)

The right things only happen by chance Parents from both groups gave numerous examples of delays in various aspects of their children's longer term care, and many suggested that finding support was a matter of chance rather than design. These stories are summarised by the following example:

"There is an issue of finding a social worker who knows all the 'doors' and how to open them. Prior to the appointment of ours we were stumbling in the dark, trying to find our own way, as nobody volunteered our rights or entitlements." (Subject 1:4)

Needing a break from the general strain Parents from both groups made references to their own needs for a break from the general pressures of caring for a disabled child. Some children from both groups had been offered little or no respite support. Those parents whose children did receive this service indicated it was beneficial but not always available when most needed, as this mother explained:

"Yes she does get respite and she loves it but it is not always at the best times for us, it would be best if we could phone and ask for specific dates ... But at least we get something." (Subject 1:12)

\section{Discussion}

Many of the emotional, psychological, and social effects of severe brain damage after cardiac surgery could have been predicted. The purpose of this study, however, was to record the consequences for families of such a catastrophe and to determine what measures can be taken to provide assistance in the short and long term. For comparison, parents of children with non-iatrogenic brain injury were interviewed, but in this report we concentrate on the particularly poignant situation of parents whose child undergoes treatment in the hope of cure but ends up neurologically damaged and in many ways worse off. Our analysis was heuristic, concerned with what brain injury meant to the parents, rather than quantitative in the usual scientific sense. Both methods are valid, even if the former is less familiar in a medical setting. One reason for our approach was that only a few people could be interviewed, making a quantitative analysis somewhat artificial. Another reason, however, was that our purpose was to see if insights derived from such an approach might result in identifying where assistance given was inadequate or could be improved.

The following subthemes were drawn from the data categorised as "emotional": "loss," "blame," "fear for one's sanity," "fear of injuring the child," and "love." The range of emotions described by both groups of parents confirms the findings of other investigators. ${ }^{9} 10$ Loss was a sensation vividly described by parents in group 1 and was a theme to which some returned repeatedly. Although most were slow to apportion blame, some said they felt inhibited, and unable to question the powerful role of medicine and physicians. These parents suffered what they called "exhaustion and devastation" at being unable to meet the needs of their children, even dreading that shear frustration and tiredness might lead them to injure their child. Clearly they required more emotional and practical support than they were given. Both in hospital and when the family returned home, someone detached from the child's daily care and independent of the hospital could be advantageous for the family and could facilitate exploration of these themes.

Seven subthemes were identified from the category entitled "social." These were: "isolation," "someone to talk to," "the pain of retelling the story," "the strange new person," "balancing the needs of various family members," "the child and the world," and "money." Essentially these themes illustrate problems within the family, and with informal and formal 
social networks and lead to questions and fears about the wider societies within which the families lived.

Within the nuclear family, if "all" disagreements centred on the "disabled child" they become a destructive and dividing force, causing the most stress in relationships where "arguments" were not seen as an integral part of the partnership. Mothers described the plight of their healthy children and experienced guilt at not having the time or energy to offer them equal attention. Other published reports show that the impact on siblings of disabled children in the family is becoming a common concern. ${ }^{11}{ }^{12}$

Isolation seemed to be generated by poor understanding, judgment, and avoidance by formal and informal networks. Frequently, parents wanted contact with other families in similar situations for empathy, understanding, and relief from absolute isolation. In some cases this seemed to be exaggerated by health services and clinicians. For example, retelling the story of their children's brain damage to every new contact was a source of pain to parents in both groups, even though they viewed it as a way to facilitate the best opportunities for their children. Subjects proposed that professionals at least could ease their burden by reading case notes, developing relationships with the family, and offering written summaries to parents at the time of the injury, so they might in turn offer these to new contacts. Families had to meet extra costs and therefore had lower financial status than they would have had. It is important that parents finding it difficult to meet extra costs could not easily identify their rights to benefits and other resources. Again an individual separate from doctors, nurses, and other health care workers directly involved in providing services might offer independent support, provide this information, and facilitate coordination of existing services.

Parents from both groups mentioned the role of society in relation to disabled children. However, the specific issues differed considerably. Subjects from group 1 raised major questions about quality of life, of death, and the role of medicine. In particular they wanted an end to what one called "the conspiracy of silence." They felt that the fate and future of children like their own should be openly discussed by society and by the medical profession. While such discussions do take place, access to written material dealing with the issues is not necessarily available for parents, let alone doctors and nurses involved in the child's care.

Four subthemes were identified in the data categorised as "professional." These were categorised as: "the crisis period," "a picture of the roads ahead," "the right things only happen by chance," and "needing a break." In many ways these themes are a chronological description of the problems faced by families with disabled children, although the particular problems of the focus group are revealed by closer examination.

Parents in group 1 specifically felt that health care workers failed to address important issues. They felt unsupported at a time when they faced the biggest, most devastating questions of their lives. In describing their initial contacts with professional carers, parents wanted practical assistance, information, and honesty. Above all they wanted to be offered a realistic view of the future, although it is not always possible to predict outcome and disability. They suggested that it would be most useful to have information about local support services. To have the information they needed within the first few weeks and to have it repeated as required and in writing. These parents did not see their general practitioners as best placed to fulfil this role; instead they suggested that it would be a valuable new role, one that should be created to meet these needs.

It is important to note that parents praised and valued the support provided by particular social workers, nurses, family, or hospital doctors, but nevertheless they described long waits for services to be established and difficulty in finding out what they were entitled to. They likened their efforts to "fights," "battles," and "struggles," suggesting that the best people were only found by chance. Respite care provided the best opportunity for a break from daily problems and was highly valued. However, it was not always directly suited to the specific needs of each family and some families had never received this service.

In conclusion, it seems that a coordinator of services for acutely brain injured children after cardiac surgery could be beneficial for families. The person concerned could provide independent emotional support and practical guidance on how best to access support services. Nothing takes away the reality of what has happened, but providing the opportunity for families to explore what this means to their subsequent lives is something for which the paediatric cardiologist or surgeon in not necessarily well equipped, particularly when they feel in part accountable for the outcome.

1 Lundar T, Lindberg H, Lindegaard KF, et al. Cerebral perfusion during major cardiac surgery in children. Pediatr Cardiol 1987;8:161-5

2 Phoon CK. Deep hypothermic circulatory arrest during cardiac surgery: effects on cerebral blood flow and cerebra oxygenation in children. Am Heart f 1993;125:1739-48.

3 Greeley WJ, Ungerleider RM, Smith LR, et al. The effects of deep hypothermic cardiopulmonary bypass and total circulatory arrest on cerebral blood flow in infants and children. In: Crupi G, Parenzan L, Anderson RH, eds. Perspectives in pediatric cardiology. Volume 2. Pediatric cardiac surgery, part 3. New York: Futura Publishing Co, 1990:208-12.

4 Ferry PC. Neurologic sequelae of open-heart surgery in children: an "irritating question." Am f Dis Child 1990;144: 369-73.

5 Fallon P, Aparicio JM, Elliott MJ, et al. Incidence of neurological complications of surgery for congenital heart neurological complications of surgery for
disease. Arch Dis Child 1995;72:418-22.

6 Derogatis LR. Psychosocial adjustment to illness scale. Derogatis LR. Psychosocial adjustment to illness
Baltimore: Clinical Psychometric Research, 1975.

7 Sarason IG, Levine HM, Basham RB, et al. Assessing social Sarason IG, Levine HM, Basham RB, et al. Assessing social
support: the social support questionnaire. $\mathcal{F}$ Pers Soc Psychol 1983;44:127-39.

8 Coffey A, Atkinson P. Making sense of qualitative data: complementary research strategies. London: Sage Publications, 1996.

9 Eden OB, Black I, Mackinlay GA, et al. Communicating with parents of children with cancer. Palliative Med 1994;8: 105-14

10 Jerrett MD. Parents' experience of coming to know the care of a chronically ill child. $\mathcal{F}$ Adv Nursing 1994;19:1050-6.

11 Carnevale FA. A description of stressors and coping strategies among parents of critically ill children-a preliminary study. In: Gott $M$, Moloney B, eds. Child health: a reader. Oxford: Radcliffe Medical Press, 1994: 280-90.

12 Dominica F Mother. The nursing care of the chronically sick or handicapped child. In: McCarthy GT, ed. Physical disability in childhood: an interdisciplinary approach to management. Singapore: Churchill Livingstone, 1992. 